\title{
Antifibrotic Alleviative Effect of Bone Marrow-Derived Mesenchymal Stem Cells on Experimentally induced Schistosoma mansoni Related Liver Fibrosis
}

\author{
Marwa Ahmed Gouda ${ }^{1 *}$, Asmaa Shams El Dein Mohamed ${ }^{2}$, \\ Fatma Eldesoky Ahmed ${ }^{3}$, Ghada Samir Amer ${ }^{4}$ and Dalia Shafey ${ }^{1}$ \\ ${ }^{1}$ Department of Clinical and Molecular Parasitology, National Liver Institute (NLI), \\ Menoufia University, Shebin Al Koom, Menoufia, Egypt \\ ${ }^{2}$ Department of Pathology, ${ }^{4}$ Department of Physiology, Faculty of Medicine, Menoufia \\ University, Shebin Alkoom, Menoufia, Egypt \\ ${ }^{3}$ Department of Clinical Pharmacology, Faculty of Medicine, Menoufia University, Shebin \\ Alkoom, Menoufia, Egypt \\ *Corresponding author
}

\section{A B S T R A C T}

\begin{tabular}{|l|}
\hline K e y w o r d s \\
BM-MSCs, \\
Schistosoma \\
mansoni, \\
Praziquantel, \\
Hyaluronic acid, $\alpha$ \\
SMA \\
\hline Article Info \\
\hline $\begin{array}{l}\text { Accepted: } \\
10 \text { November } 2019 \\
\text { Available Online: } \\
\text { 10 December } 2019\end{array}$ \\
\hline
\end{tabular}

With increased national programs for eliminating schistosomiasis and viruses affecting the liver in Egypt, treating the remained pathology represented mainly by liver fibrosis will probably be a competitive goal in the coming few years. We aimed in our work to reinforce the antifibrotic effect of BM-MSCs in liver fibrosis related to Schistosoma mansoni (Egyptian strain) infection in murine model and correlating serum Hyaluronic acid (HA) to liver fibrosis. A pilot study was done first to ensure reaching of MSCs to the fibrosed liver tissues following infection with S. mansoni and secondly to detect the best route for MSCs inoculation. Then 70 female Swiss albino mice were divided into five groups. GI; uninfected untreated, $(\mathrm{NC}, \mathrm{n}=10)$, infected mice were categorized into 4 groups each contained 15 mice regarding treatment at 6 th week p.i; GII: Infected untreated, GIII: PZQ treated, GIV: received MSCs and GV: PZQ then MSCs treated. Sacrifaction of all mice at $14^{\text {th }}$ week p.i. was done and mice were subjected to parasitological, biochemical, histological and immunohistochemical workup. We observed that the use of BMMSCs and PZQ significantly decreased mean granuloma number, with significant reduction in fibrosis percent (Masson trichrome) staining than PZQ. Presence of fibrosis was associated with high serum HA level and reduction of fibrosis was linked to lowering its serum levels. Use of the combined treatment improved liver function tests. Intravenous route for administration of MSCs and the use of HA as a noninvasive marker of fibrosis are recommended. MSCs significantly alleviate liver fibrosis induced by Schistosoma mansoni infection. 


\section{Introduction}

Schistosomiasis has global importance as a parasitic disease. It is a considerable reason for morbidity and mortality worldwide (Johnston, Teague, and Graham 2015). More than 220 million people are infected with various types of Schistosoma, about seven hundred million people are in danger of being infected in 52 countries (James et al., 2018).The disease is usually represented pathologically by chronic inflammation, focal areas with excess extracellular matrix (ECM)that is deposited in peri-ovular granulomas and distributed in variable numbers at the portal venous system periphery (Colley et al., 2014). Host reaction to parasite eggs laid in the venous portal system and then trapped in the liver and intestine is primarily responsible for the main pathology of Schistosomiasis mansoni which lead to hepatic fibrotic changes causing dangerous complications such as, hepatomegaly, portal hypertension and oesophageal varices with hemorrhage tendency that are frequently the main cause of death (Chuah et al., 2014).

Praziquantel (PZQ) is the anti-Schistosomiasis drug used for more than forty years now; Its effectiveness against adult worms of all schistosome species is known to be more than against immature larvae (Cioli et al., 2014). Besides, low capacity is shown to reverse tissue damage or liver fibrosis caused by schistosome eggs (Singh et al., 2004).

A large number of drugs with known antifibrotic action in vivo and in vitro were tried to reverse liver fibrosis with no applicable results for clinical use (Liu et al., 2015).Thus transplantation of healthy liver remains the sole regimen for end-stage liver disease. Multi-differentiation potential, regenerative activity, modulation of immune response and capability of self-renewal, putsmesenchymal stem cells (MSCs)in the focus of liver fibrosis treatment strategies (Zhang et al., 2018; Zhao et al., 2018). Transdifferentiation of hepatic stellate cells into myofibroblasts is a key factor in liverfibrosis (Carson et al., 2018). An indicator of activation of hepatic stellate cells (HSC) is the expression of alpha-smooth muscle actin ( $\alpha$ SMA) in the liver and is recognized as the main player in liver fibrogenesis (Sun et al., 2015)

The potential role of stem cell transplantation was tested by some authors, with the capacity of transdifferentiation into hepatocytes which help in the regeneration of liver tissue. Immunohistochemical markers such as $\alpha$ SMA supported reduction of fibrosis ( $\mathrm{Xu}$ et al., 2012).

Hyaluronic acid is mainly synthesized by HSCs and its importance comes from avoidance of liver biopsy if used to detect degree of fibrosis (Tamaki et al., 1996 and Suzuki et al., 2005).

Herein, we aimed to reinforce the role of BMMSCs transplantation in the management of Schistosomiasis mansoni related liver fibrosis and evaluate the role of $\mathrm{HA}$ as marker of fibrosis.

\section{Materials and Methods}

This study was conducted in the Department of Molecular and Clinical Parasitology National Liver Institute Menoufia University in collaboration with Bilharz Research Institute (TBRI), Giza, Egypt, from May 2017 to June 2019.

\section{Ethics statement}

The current study was performed in line with the international policy and acceptance of animal ethics committee Tudor Bilharz Research Institute (TBRI), Giza, Egypt. 


\section{Experimental mice}

One hundred and eleven Swiss albino mice (Musmusculus), 6-8 weeks old, laboratorybred weighing approximately $25 \mathrm{gm}$, (30 male mice selected as BM-MSC donors and 81 female mice) were used in the study. They were brought and housed in a designated and government- approved animal house at Theodor Bilharz Research Institute, Giza, Egypt.

All efforts were made to minimize animal suffering. The mice were kept in wired cages under appropriate housing and handling conditions.

They were given a standard eating regimen according to the regulations of animal ethical committee (TBRI).

\section{Infection of mice with $S$. mansoni}

Female mice (71) mice were infected via injecting 50-60 cercariae delivered from infected Biomphalaria alexandrina snails and subcutaneously injected in each mouse(Peters and Warren 1969).

At $6^{\text {th }}$ week post-infection (p.i.), one mouse was sacrificed and its liver was stained with Haematoxylin and Eosin $(\mathrm{H} \& \mathrm{E})$ to find out whether the infection succeeded to produce fibrosis or not. Pathological examination of the liver tissue proved the presence of fibrosis.

\section{Drugs}

\section{Praziquantel}

Distocide (EPICO, Egypt) was administered for praziquantel (PZQ) group, the drug was administered in the form of aqueous suspension orally to each mouse by gavage through the mouth (Jiraungkoorskul et al., 2005).

\section{Mesenchymal stem cells (MSCs)}

\section{Bone marrow MSCs isolation and culture}

Isolation of Bone marrow mesenchymal stem cells (BM-MSCs) was done according to Soleimani and Nadri (2009). The isolated cells were initially seeded at a density of $1.5 \times 10^{6}$ cells/well into 6-well plate utilizing complete DMEM that contains low glucose Dulbecco's Modified Eagle's Medium (DMEM) (Lonza, Visp, Switzerland) supplemented with 30\% fetal bovine serum (Hyclone, USA), $1 \%$ penicillin/streptomycin (Biochrom, Berlin, Germany), and 1\% L-glutamine (Lonza). Incubation was done in an atmosphere of 5\% $\mathrm{CO} 2$ and $90 \%$ relative humidity at $37^{\circ} \mathrm{C}$.

The wells were examined after ten days to detect colony formation. Media change for the first time was done after two weeks, then twice weekly.

After reaching the cells 95\% confluency, trypsinization was done using $0.25 \%$ trypsin (Euro-lone, Milan, Italy). Cells were transferred after plating to the first passage by culturing at seeding density 5000 cells $/ \mathrm{cm}^{2}$.

When 80 - 90\% confluency was reached, trypsinization was done and cells were cultured at the same density and transferred to the next passage till reaching senescence (Soleimani and Nadri 2009). MSCs were administered in a single dose of $1 \times 10^{6}$ Cells/mouse.

\section{MSCs immunophenotyping}

Staining of Cells from the $4^{\text {th }}$ passage with fluorescein isothiocyanate (FITC) rat antimouse CD90, CD 44, CD31 and CD 45 (BD Biosciences, San Jose, CA, USA) for 30 minutes, then final analysis using flow cytometer was done (Beckman Coulter Epics XL-MCL). 


\section{Experiment protocol}

\section{Pilot study}

A pilot study was performed before proceeding this work aiming to; determine the route of MSCs administration either through hepatic or intravenous injection (I.V.) and ensure reaching of administered MSCs. to the liver.

250 microns of Labeled MSCs with red fluorochrome PKH26 (Sigma- Aldrich Co., USA) suspended in phosphate buffer solution (PBS) was injected in the tail vein of five mice and intrahepatically to another five mice 6 weeks p.i. with $S$. mansoni cercaria (50- 60 per mouse) which were injected subcutaneously. Mice were sacrificed at $14^{\text {th }}$ week p.i., and the livers were harvested and examined under a fluorescence microscope. The number of labeled BM-MSC was estimated after excision of parts of the livers, snap-frozen in liquid nitrogen and cut into $5 \mathrm{~mm}$ sections to be examined using a fluorescence microscopy (Yang et al., 2009).

Statistical analysis was done and we found that there was no significant difference between intrahepatic and intravenous injection of MSCs as the route of infection, although intrahepatic route appeared to be more invasive and require more skilled personnel to minimize the suffering of animals thus in this study we depend on the intravenous injection of MSCs.

Mice were classified into; Group I; uninfected untreated, negative control, ( $\mathrm{NC}, \mathrm{n}=10)$, then the remaining infected mice (60 mice) were randomly categorized into; Group II: Infected untreated positive control group (PC, $n=15$ ), Group III: Infected, treated with PZQ at 6th week p.i. (PZQ, n=15), Group IV: Infected, received MSCs 6th week p.i. (MSCs, $n=15$ ) and Group V: Infected, treated at $6^{\text {th }}$ week p.i. with PZQ then received MSCs. And (PZQ+ MSCs, $\mathrm{n}=15$ ). Cervical dislocation was done for all the mice $14^{\text {th }}$ week p.i. and blood was quickly gathered by heart's puncture. It was kept at room temperature for twenty minutes, there after samples were centrifuged at 2000 rpm for 15 minutes for collection of serum and were stored in aliquots at $-80^{\circ} \mathrm{C}$.

\section{Parasitological and morphological parameters}

Weighing the liver and spleen in addition to the body of each mouse was done. Liver and spleen indices were calculated according to the ratio of liver weight to whole body weight and spleen weight to whole body weight respectively. After mice scarification, the adult worms were perfused from the liver and porto-mesenteric vessels (Duvall and DeWitt 1967). Small portions of the liver and intestine were weighted, left overnight at $37^{\circ} \mathrm{C}$ in five percent of $\mathrm{KOH}$ and calculated the mean number of eggs per gram of tissue (Cheever 1968).

\section{Histopathological analysis}

After the standard procedure, the liver portions of the euthanized mice were stained with hematoxylin and eosin (H\&E). The specimens were fixed in ten percent formalin and then dehydrated before washing with xylene in ascending alcohol grades. In molten paraffin wax, the dehydrated tissues were embedded and then cut into thin sections. The sections were mounted on clean glass slides and stained with H\&E. By using a low magnification power the number of liver granulomas was counted in randomly picked out five microscopic field/ liver sections for each mouse. Sections usually were seen per mouse. The mean number of egg granulomas in the liver section was calculated (Ali and Hamed, 2006). 
Measuring the degree of hepatic fibrosis by Masson's trichrome staining \& $\alpha$ SMA

Liver sections stained with Masson's trichrome were utilized to estimate the degree of hepatic fibrosis. Paraffinized liver samples were stained following the manufacturer's instructions using Masson's trichrome staining kit (Sigma-Aldrich, St. Louis, USA).

By applying the image $\mathbf{J}$ software program, version $1.47 \mathrm{v}$, the percentage of fibrosis was calculated using photos taken for mice group liver slides. In liver tissues of all mice groups, a SMA immunostaining was performed using the standard avidin-biotin immunoperoxidase immunohistochemical method.

\section{Measuring some biochemical markers for liver function\& fibrosis}

Assessment of liver function tests including alanine aminotransferase (ALT), alkaline phosphatase (ALP) and albumin was done using Beckman Coulter Olympus AU480 automated chemistry analyzer (Beckman Instrument Inc. Fullerton, California USA) in the serum of mice of all groups. Using Enzyme-linked immunosorbent assay (ELISA) the serum level of HA was detected according to manufacturer instructions (R\&D System, Inc, USA).

\section{Statistical data analysis}

Data were analyzed using the SPSS program (Statistical Package for the Social Sciences, version 20 for Windows) software (SPSS Inc., Chicago, Illinois, USA). Our results were conferred as mean \pm standard deviation (SD). Percentage of reduction (PR) in mice treated groups $=(\mathrm{C}-\mathrm{T} / \mathrm{C}) \times 100$, where $\mathrm{C}$ refers to mean of IU mice group and mean of the treated mice group represented as T. Mann Whitney $\mathrm{U}$ test was used as a non-parametric measurement of data for comparison between the studied groups as pairs. P-value of less than 0.05 was considered a significant result.

\section{Results and Discussion}

World Health Organization (WHO), has listed seventeen diseases as ignored tropical disease, one of them is Schistosomiasis which has lethal sequelae resulting in liver fibrosis with a high rate of morbidity and mortality (Hotez et al., 2014 \&Vos et al., 2016). Scientists found that MSCs therapy represents a new era in the management of chronically diseased liver which has been under research lately.

Mainly immune modulation, inhibiting fibrogenesis and transformation are the possible ways by which regeneration of liver occurs (Kang et al., 2019).

Success in treatment with MSCs could substitute liver transplantation which appears to be the sole treatment of liver cirrhosis but lack of donor's, surgical producers complication and high cost restrict this choice of treatment (Zhang et al., 2019).

\section{Bone marrow MSCs isolation and culture}

Successful isolation of MSCs from mice bone marrow was done. After seeding, on the $14^{\text {th }}$ day elongated adherent cells were observed (Fig. 1). BM-MSCs showed high expression levels of adhesion marker (CD44) and typical mesenchymal markers (CD90) whereas they were negative for endothelial cell marker (CD31), Leukocyte common antigen (CD45).

Using fluorescent microscopy, labeled cells with PKH26 dye were reported in the liver cells which indeed ensure the presence of MSCs that have been transplanted. Anan et al., (2016) and Hegab et al., (2018), also used the same method to emphasize the presence of MSCs in liver tissue following transplantation. 


\section{Parasitological and morphological parameters}

PC group have a lower weight compared to $\mathrm{NC}$ group. Mice weights were increased in all treated groups $(24.4 \pm 2.7,22.94 \pm 2.14$ and $27.4 \pm 1.67$ in PZQ, MSCS and MSCS\&PZQ respectively) compared to infected untreated group (18.8 \pm 1.48$)$, P-values were $0.02,0.02$ and 0.009 respectively (Table 1 ).

The liver index was significantly increased in infected mice compared to the uninfected group $(\mathrm{P}=0.009)$ and after treatment, it showed no significant changes except in the MSCS group ( $\mathrm{P}=0.03$ ) compared to untreated mice. Mice weight in MSCs group was lower than combined group (BM-MSCs/PZQ) which may explain the significant difference in our study.

Regarding the splenic index, it was highly elevated in the infected group than in uninfected one $(\mathrm{P}=0.009)$ which was followed by a significant reduction in all treated groups PZQ, MSCs and BM-MSCs/PZQ (P-value was $0.009,0.047$ and 0.009 respectively) (Table 1). Splenic index was decreased in the present work in BM-MSCs/PZQ treated group more effectively may be due to combined antiSchistosomal with antifibrotic activity this is going with the results of $\mathrm{Xu}$ et al., (2012) who also reported a significant reduction in splenic index after BM-MSCs based therapy (Table 1).

S. mansoni eggs were recognized in mice feces before starting treatment. The total worm burden recovered by perfusion of sacrificed animals was counted and analyzed. The mean worm count was statistically reduced in all groups compared to infected the untreated group with $P=0.008$. MSCs treated group mean worm count was 7.6 \pm 0.89 followed by combined treated group $1.0 \pm 1.0$ and lastly PZQ treated group with mean worm count of $0.8 \pm 0.82$ however, it was $20.6 \pm 1.67$ in the untreated group. Egg count per gram in the liver and intestine tissues was also reduced with a significant difference in all treated groups $p$ value $<0.001$ (Table 2 ). These results were consistent to results obtained by ElMahdi et al., (2014), they stated that egg number correlated to severity of disease and is associated with either decrease with decreasing liver fibrosis. Percent of reduction in total worm count, egg count in liver tissue and egg count in intestinal tissue was higher in PZQ and combined treated groups than in MSCs alone treated group (Table 2), which could be explained by lack of direct antiSchistosomal effect on adult worm compared to the effect PZQ treatment.

\section{Serum liver biomarkers}

Infected untreated mice showed a significant rise in serum ALT $(95.0 \pm 23.95)$ than uninfected control $(27.8 \pm 3.7)$ together with a significant decrease in serum Albumin levels $(1.98 \pm 0.7)$ and increase in serum ALP $(60.2 \pm 16.16)$. Levels of these biomarkers in serum were affected in different values after treatment regimens, as shown in Table 1. ALT level was decreased with PZQ therapy (40.2 \pm 2.8$)$, with significant statistical difference compared with the infected untreated control $(P=0.009)$. A significant reduction in the ALT level $(37.8 \pm 3.03)$ was reported in mice given $\mathrm{PZQ} / \mathrm{MSCs}$ as well as MSCs only (38.8 \pm 2.59$) P=0.009$. ALP level in serum decreased in the PZQ group (41.2 \pm 3.83$)$, MSCs therapy (40.2 \pm 5.93$)$ and combined PZQ/MSCs group (39.8 \pm 1.92$)$. Moreover, a significant increase in albumin level was also noted in groups treated either with PZQ alone, MSCs alone or combined treatment referred to infected group $(3.56 \pm 0.38, \quad 4.05 \pm 0.39, \quad$ and $3.86 \pm 0.06$ respectively) (Table 1). 
Table.1 Comparison between the studied groups regarding Lab tests

\begin{tabular}{|c|c|c|c|c|c|c|c|}
\hline & \multicolumn{5}{|c|}{ The studied groups } & \multirow[t]{2}{*}{$\mathbf{U}$} & \multirow[t]{2}{*}{ P Value } \\
\hline & $\begin{array}{c}\mathrm{NC} \\
\mathbf{N}=\mathbf{1 0}\end{array}$ & $\begin{array}{c}P C \\
N=15\end{array}$ & $\begin{array}{c}\text { PZQ } \\
\text { N }=15\end{array}$ & $\begin{array}{l}\text { MSCS } \\
\mathrm{N}=15\end{array}$ & $\begin{array}{c}\text { MSCS\&PZQ } \\
\quad \mathrm{N}=15\end{array}$ & & \\
\hline $\begin{array}{c}\text { WT } \\
X \pm \text { SD } \\
\text { Range }\end{array}$ & $\begin{array}{l}26.2 \pm 0.76 \\
25.5-27\end{array}$ & $\begin{array}{c}18.8 \pm 1.48 \\
0.17-0.21\end{array}$ & $\begin{array}{c}24.4 \pm 2.7 \\
20-27\end{array}$ & $\begin{array}{l}22.94 \pm 2.14 \\
20.8-25.4\end{array}$ & $\begin{array}{c}27.4 \pm 1.67 \\
26-30\end{array}$ & $\begin{array}{l}2.64 \\
2.41 \\
2.31 \\
2.63\end{array}$ & $\begin{array}{c}0.008^{1} \\
0.02^{2} \\
0.02^{3} \\
0.009^{4}\end{array}$ \\
\hline $\begin{array}{c}\text { ALT } \\
\text { X } \pm \text { SD } \\
\text { Range }\end{array}$ & $\begin{array}{c}27.8 \pm 3.7 \\
23-32\end{array}$ & $\begin{array}{c}95.0 \pm 23.95 \\
61-120\end{array}$ & $\begin{array}{c}40.2 \pm 2.8 \\
38-45\end{array}$ & $\begin{array}{c}38.8 \pm 2.59 \\
36-42\end{array}$ & $\begin{array}{c}37.8 \pm 3.03 \\
34-42\end{array}$ & $\begin{array}{l}2.61 \\
2.61 \\
2.61 \\
2.61\end{array}$ & $\begin{array}{l}0.009^{1} \\
0.009^{2} \\
0.009^{3} \\
0.009^{4}\end{array}$ \\
\hline $\begin{array}{c}\text { Albumin } \\
\text { X } \pm \text { SD } \\
\text { Range }\end{array}$ & $\begin{array}{c}3.42 \pm 1.48 \\
3.2-3.6\end{array}$ & $\begin{array}{l}1.98 \pm 0.7 \\
1.2-2.3\end{array}$ & $\begin{array}{c}3.56 \pm 0.38 \\
3.1-3.9\end{array}$ & $\begin{array}{c}4.05 \pm 0.39 \\
3.5-4.6\end{array}$ & $\begin{array}{l}3.86 \pm 0.06 \\
3.8-3.91\end{array}$ & $\begin{array}{l}2.63 \\
2.63 \\
2.63 \\
2.64\end{array}$ & $\begin{array}{l}0.009^{1} \\
0.009^{2} \\
0.009^{3} \\
0.008^{4}\end{array}$ \\
\hline $\begin{array}{c}\text { ALP } \\
\mathrm{X} \pm \text { SD } \\
\text { Range }\end{array}$ & $\begin{array}{c}38.6 \pm 1.67 \\
36-40\end{array}$ & $\begin{array}{c}60.2 \pm 16.16 \\
47-86\end{array}$ & $\begin{array}{c}41.2 \pm 3.83 \\
39-48\end{array}$ & $\begin{array}{c}40.2 \pm 5.93 \\
32-48\end{array}$ & $\begin{array}{c}39.8 \pm 1.92 \\
38-43\end{array}$ & $\begin{array}{l}2.62 \\
2.42 \\
2.19 \\
2.41\end{array}$ & $\begin{array}{c}0.009^{1} \\
002^{2} \\
0.03^{3} \\
0.02^{4}\end{array}$ \\
\hline $\begin{array}{l}\text { Liver } \\
\text { index } \\
\mathrm{X} \pm \mathrm{SD} \\
\text { Range }\end{array}$ & $\begin{array}{l}0.05 \pm 0.005 \\
0.04-0.06\end{array}$ & $\begin{array}{c}0.07 \pm 0.01 \\
0.07-0.09\end{array}$ & $\begin{array}{c}0.07 \pm 0.02 \\
0.05-0.09\end{array}$ & $\begin{array}{l}0.09 \pm 0.008 \\
0.08-0.11\end{array}$ & $\begin{array}{c}0.06 \pm 0.009 \\
0.06-0.08\end{array}$ & $\begin{array}{l}2.61 \\
0.31 \\
2.19 \\
0.94\end{array}$ & $\begin{array}{c}0.009^{1} \\
0.75^{2} \\
0.03^{3} \\
0.35^{4}\end{array}$ \\
\hline $\begin{array}{l}\text { Spleen } \\
\text { index } \\
X \pm S D \\
\text { Range }\end{array}$ & $\begin{array}{c}0.006 \pm 0.002 \\
0-0.01\end{array}$ & $\begin{array}{c}0.018 \pm 0.003 \\
0.01-0.02\end{array}$ & $\begin{array}{c}0.007 \pm 0.003 \\
0-1.0\end{array}$ & $\begin{array}{c}0.012 \pm 0.003 \\
0.01-0.02\end{array}$ & $\begin{array}{c}0.009 \pm 0.002 \\
0.01-0.01\end{array}$ & $\begin{array}{l}2.63 \\
2.61 \\
1.99 \\
2.62\end{array}$ & $\begin{array}{l}0.009^{1} \\
0.009^{2} \\
0.047^{3} \\
0.009^{4}\end{array}$ \\
\hline
\end{tabular}

Liver index $=$ Liver/Wt.

Splenic index $=$ Spleen $/ \mathrm{Wt}$.

$\mathrm{U}=$ Mann Whitney U test

1= Comparing negative control with positive control group; 2=Comparing PC with PZQ;

$3=$ Comparing PC with MSCS; 4= Comparing PC with MSCS\&PZQ

Table.2 Comparison between the studied groups regarding egg and worm count

\begin{tabular}{|c|c|c|c|c|c|c|}
\hline & \multicolumn{4}{|c|}{ The studied groups } & \multirow[t]{2}{*}{$\mathbf{U}$} & \multirow[t]{2}{*}{ P Value } \\
\hline & $\begin{array}{c}\mathrm{PC} \\
\mathrm{N}=15\end{array}$ & $\begin{array}{c}\text { PZQ } \\
\mathrm{N}=15\end{array}$ & $\begin{array}{l}\text { MSCS } \\
N=15\end{array}$ & $\begin{array}{c}\text { MSCS\&PZQ } \\
\mathbf{N}=15\end{array}$ & & \\
\hline $\begin{array}{c}\text { Egg count/gram intestine } \\
X \pm \text { SD } \\
\text { Range }\end{array}$ & $\begin{array}{c}18429.4 \pm 4269.2 \\
12345-23546\end{array}$ & $\begin{array}{c}1514.6 \pm 392.6 \\
1109-2123\end{array}$ & $\begin{array}{c}6845.0 \pm 2147.0 \\
4356-9765\end{array}$ & $\begin{array}{c}1617.4 \pm 326.5 \\
1190-1979\end{array}$ & $\begin{array}{l}2.61 \\
2.61 \\
2.61\end{array}$ & $\begin{array}{l}0.009^{1} \\
0.009^{2} \\
0.009^{3}\end{array}$ \\
\hline PR & & $91.78 \%$ & $62.86 \%$ & $91.22 \%$ & & \\
\hline $\begin{array}{c}\text { Egg count/gram liver } \\
X \pm \text { SD } \\
\text { Range }\end{array}$ & $\begin{array}{c}16485.8 \pm 4666.7 \\
11234-21765\end{array}$ & $\begin{array}{c}1382.4 \pm 378.7 \\
987-1917\end{array}$ & $\begin{array}{c}6038.8 \pm 786.7 \\
4963-7102\end{array}$ & $\begin{array}{c}1441.8 \pm 265.4 \\
1132-1754\end{array}$ & $\begin{array}{l}2.61 \\
2.61 \\
2.61\end{array}$ & $\begin{array}{l}0.009^{1} \\
0.009^{2} \\
0.009^{3}\end{array}$ \\
\hline PR & & $91.61 \%$ & $63.37 \%$ & $91.25 \%$ & & \\
\hline $\begin{array}{c}\text { Total worm count } \\
\text { X } \pm \text { SD } \\
\text { Range }\end{array}$ & $\begin{array}{c}20.6 \pm 1.67 \\
19-23\end{array}$ & $\begin{array}{c}0.8 \pm 0.82 \\
0-2\end{array}$ & $\begin{array}{c}7.6 \pm 0.89 \\
7-9\end{array}$ & $\begin{array}{c}1.0 \pm 1.0 \\
0-2\end{array}$ & $\begin{array}{l}2.64 \\
2.66 \\
2.64\end{array}$ & $\begin{array}{l}0.008^{1} \\
0.008^{2} \\
0.008^{3}\end{array}$ \\
\hline PR & & $96.12 \%$ & $63.11 \%$ & $95.14 \%$ & & \\
\hline
\end{tabular}

U= Mann Whitney U test; 1=Comparing PC with PZQ; 2=Comparing PC with MSCS; $3=$ Comparing PC with MSCS\&PZQ; PR= Percent of reduction 
Table.3 Comparison between the studied groups regarding histopathological parameters

\begin{tabular}{|c|c|c|c|c|c|c|}
\hline & \multicolumn{4}{|c|}{ The studied groups } & \multirow[t]{2}{*}{$\mathbf{U}$} & \multirow[t]{2}{*}{ P Value } \\
\hline & $\begin{array}{c}P C \\
N=15\end{array}$ & $\begin{array}{c}\text { PZQ } \\
N=15\end{array}$ & $\begin{array}{l}\text { MSCS } \\
N=15\end{array}$ & $\begin{array}{c}\text { MSCS\&PZQ } \\
\quad \mathbf{N}=15\end{array}$ & & \\
\hline $\begin{array}{c}\text { Mean numberof } \\
\text { granuloma } \\
\mathbf{X} \pm \text { SD } \\
\text { Range }\end{array}$ & $\begin{array}{l}13.62 \pm 3.24 \\
11.2-19.2\end{array}$ & $\begin{array}{l}6.9 \pm 0.16 \\
6.7-6.9\end{array}$ & $\begin{array}{l}17.08 \pm 3.61 \\
11.5-20.4\end{array}$ & $\begin{array}{c}4.28 \pm 1.82 \\
1.3-6\end{array}$ & $\begin{array}{l}2.61 \\
1.26 \\
2.61\end{array}$ & $\begin{array}{c}0.009^{1} \\
0.21^{2} \\
0.009^{3}\end{array}$ \\
\hline $\begin{array}{c}\text { Mean size of granuloma } \\
\text { X } \pm \text { SD } \\
\text { Range }\end{array}$ & $\begin{array}{c}272.2 \pm 11.17 \\
261-286\end{array}$ & $\begin{array}{c}265.2 \pm 0.0 \\
265.2- \\
265.2\end{array}$ & $\begin{array}{l}254.9 \pm 70.65 \\
177.6-360.2\end{array}$ & $\begin{array}{c}243.64 \pm 58.8 \\
188.2-314.2\end{array}$ & $\begin{array}{l}0.56 \\
0.52 \\
0.31\end{array}$ & $\begin{array}{l}0.56^{1} \\
0.60^{2} \\
0.73^{3}\end{array}$ \\
\hline $\begin{array}{c}\text { Percent of fibrosis by } \\
\text { Masson trichrome stain } \\
\text { X } \pm \text { SD } \\
\text { Range }\end{array}$ & $\begin{array}{c}19.51 \pm 3.48 \\
15.17-23.14\end{array}$ & $\begin{array}{c}14.80 \pm 6.94 \\
5.35-24.24\end{array}$ & $\begin{array}{c}12.3 \pm 0.0 \\
12.3-12.3\end{array}$ & $\begin{array}{c}12.63 \pm 1.97 \\
10.65-15.58\end{array}$ & $\begin{array}{l}1.27 \\
2.59 \\
2.40\end{array}$ & $\begin{array}{c}0.21^{1} \\
0.005^{2} \\
0.02^{3}\end{array}$ \\
\hline $\begin{array}{c}\text { H-score of SMA } / 300 \\
\text { X } \pm \text { SD } \\
\text { Range }\end{array}$ & $\begin{array}{c}100.0 \pm 30.82 \\
70-140\end{array}$ & $\begin{array}{c}65.0 \pm 15.81 \\
50-90\end{array}$ & $\begin{array}{c}32.0 \pm 14.4 \\
15-50\end{array}$ & $\begin{array}{c}15.0 \pm 0.0 \\
15-15\end{array}$ & $\begin{array}{l}2.01 \\
2.61 \\
2.80\end{array}$ & $\begin{array}{l}0.045^{1} \\
0.009^{2} \\
0.005^{3}\end{array}$ \\
\hline
\end{tabular}

U= Mann Whitney U test

$1=$ Comparing $\mathrm{PC}$ with $\mathrm{PZQ}$

2=Comparing PC with MSCS

$3=$ Comparing PC with MSCS\&PZQ

Table.4 Hyaluronic acid level in different studied groups

\begin{tabular}{|c|c|c|c|c|c|c|c|}
\hline & & \multicolumn{4}{|c|}{ The studied groups } & \multirow[t]{2}{*}{$\mathbf{U}$} & \multirow[t]{2}{*}{ P Value } \\
\hline & $\begin{array}{c}\mathrm{NC} \\
\mathrm{N}=10\end{array}$ & $\begin{array}{c}P C \\
N=15\end{array}$ & $\begin{array}{c}\text { PZQ } \\
\mathrm{N}=15\end{array}$ & $\begin{array}{l}\text { MSCS } \\
\mathrm{N}=15\end{array}$ & $\begin{array}{c}\text { MSCS\&PZQ } \\
\quad \mathrm{N}=15\end{array}$ & & \\
\hline $\begin{array}{c}\text { Hyaluronic acid } \\
\text { X } \pm \text { SD } \\
\text { Range }\end{array}$ & $\begin{array}{c}10.74 \pm 1.18 \\
9-12\end{array}$ & $\begin{array}{c}44.6 \pm 14.84 \\
30-65\end{array}$ & $\begin{array}{c}35.0 \pm 5.96 \\
30-45\end{array}$ & $\begin{array}{c}25.2 \pm 4.20 \\
20-30\end{array}$ & $\begin{array}{c}22.4 \pm 2.7 \\
18-25\end{array}$ & $\begin{array}{l}2.88 \\
0.95 \\
2.51 \\
2.61\end{array}$ & $\begin{array}{c}<0.001^{1} \\
0.34^{2} \\
0.01^{3} \\
0.009^{4}\end{array}$ \\
\hline
\end{tabular}

$\mathrm{U}=$ Mann Whitney $\mathrm{U}$ test

$1=$ Comparing negative control with positive control group

2=Comparing $\mathrm{PC}$ with PZQ

3=Comparing PC with MSCS

4= Comparing PC with MSCS\&PZQ 
Fig.1 MSCs appearing as spindle shaped fibroblast-like under inverted tissue microscope

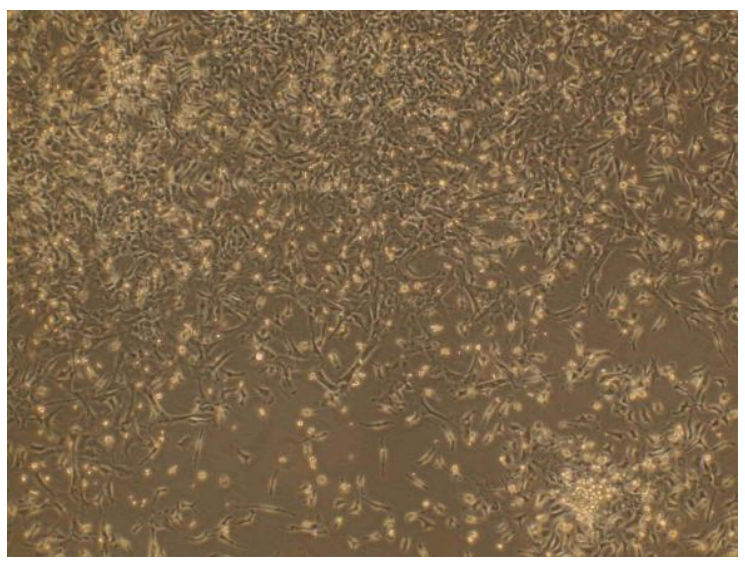

Fig.2 Section of liver tissue treated with PZQ showing multiple variable sized and shaped bilharzial granuloma (circles) with central calcified bilharzial ova surrounded by dense fibrosis and chronic inflammatory infiltrate (H\&E x100)

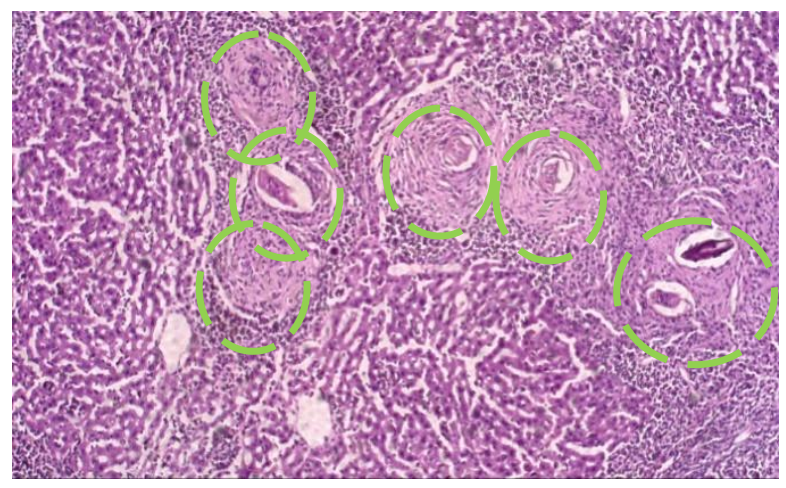

Fig.3 A; Section of liver tissue of PZQ group showed multiple bilharzial granuloma with areas of fibrosis highlighted by Masson trichrome stain (Masson trichrome x100). B; SMA immunostaining of the same group showed moderate fibrosis and mesenchymal stromal cells (SMA x100)

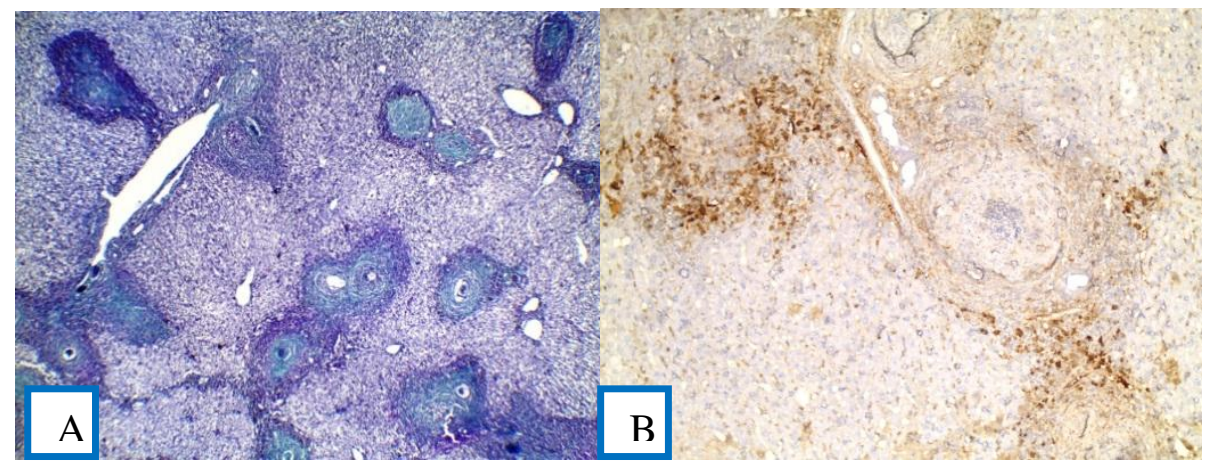


Fig.4 A; Section of liver tissue of positive control group showed large number of bilharzial granuloma with wide areas of fibrosis highlighted by Masson Trichrome stain (Masson Trichromax 100). B; $\alpha$ SMA immunostaining of the same group showed high percent of fibrosis and mesenchymal stromal cells ( $\alpha$ SMA x 100)

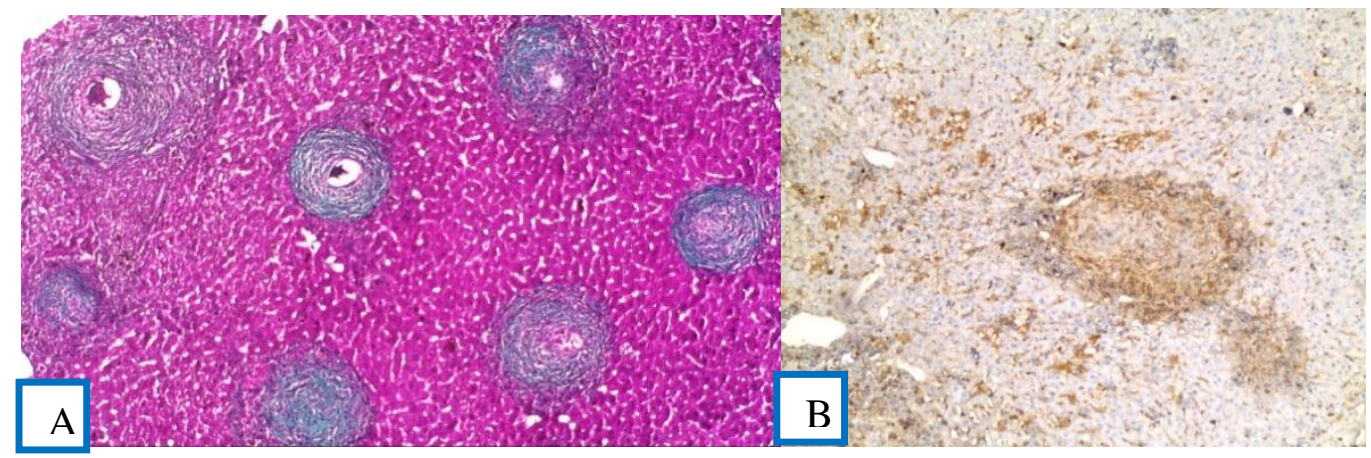

Fig.5 A; Section of liver tissue of MSCs group showed large number of bilharzial granuloma with scattered areas of fibrosis highlighted by Masson Trichrome stain (Masson Trichromax 100). B; $\alpha$ SMA immunostaining of the same group showed granulomas with moderate fibrosis and many mesenchymal stromal cells ( $\alpha$ SMA x100)

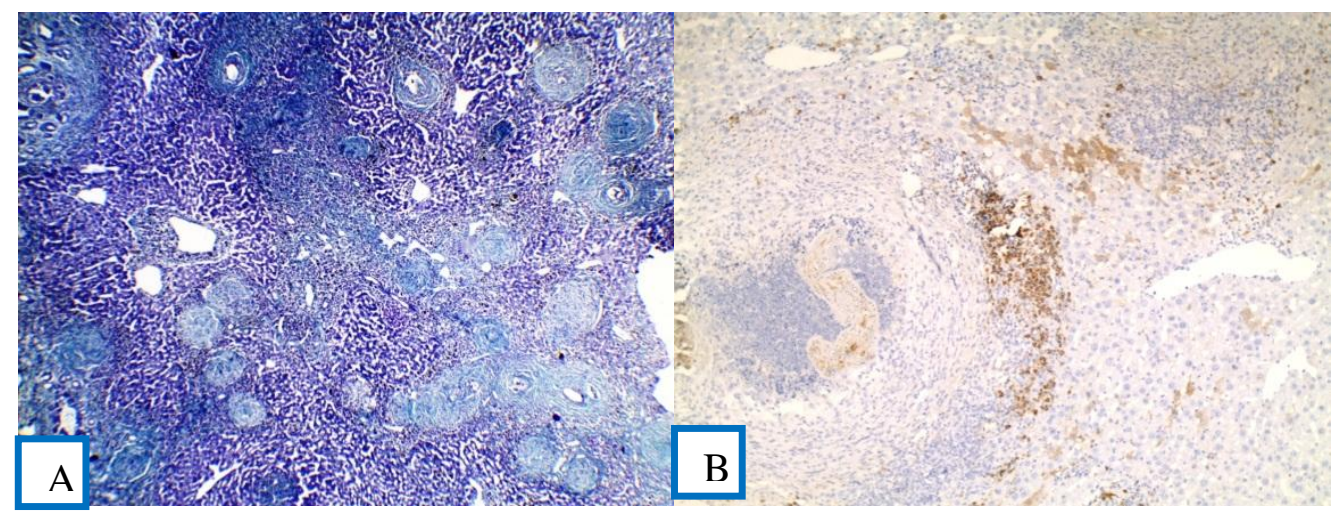

Fig.6 A; Section of liver tissue of (MSCS \& PZQ) group showed few number of bilharzial granuloma with small areas of fibrosis highlighted by Masson trichrome stain (Masson Trichromax100). B; $\alpha$ SMA immunostaining of the same group showed moderate fibrosis and mesenchymal stromal cells ( $\alpha$ SMA x 100)

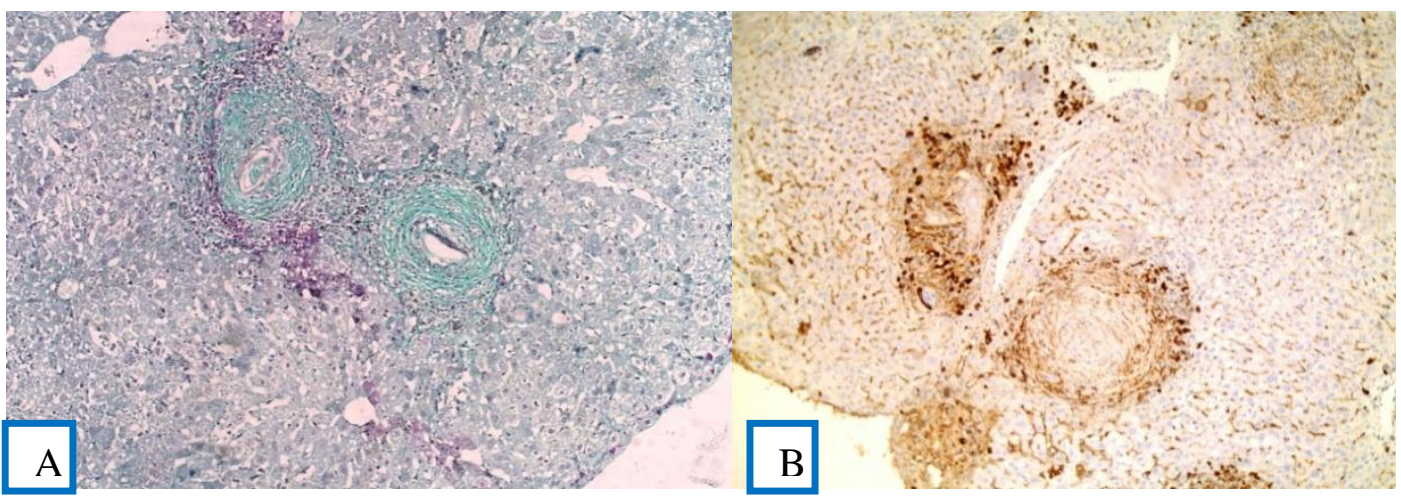


Fig.7 Showing HA level between different studied groups

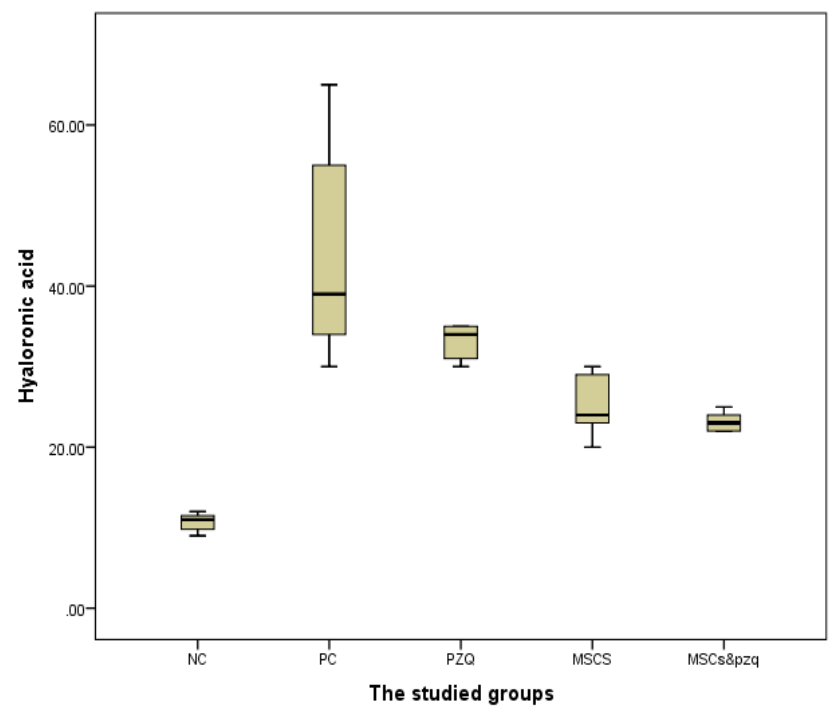

Fig.8 Comparison between studied groups regarding $\alpha$ SMA

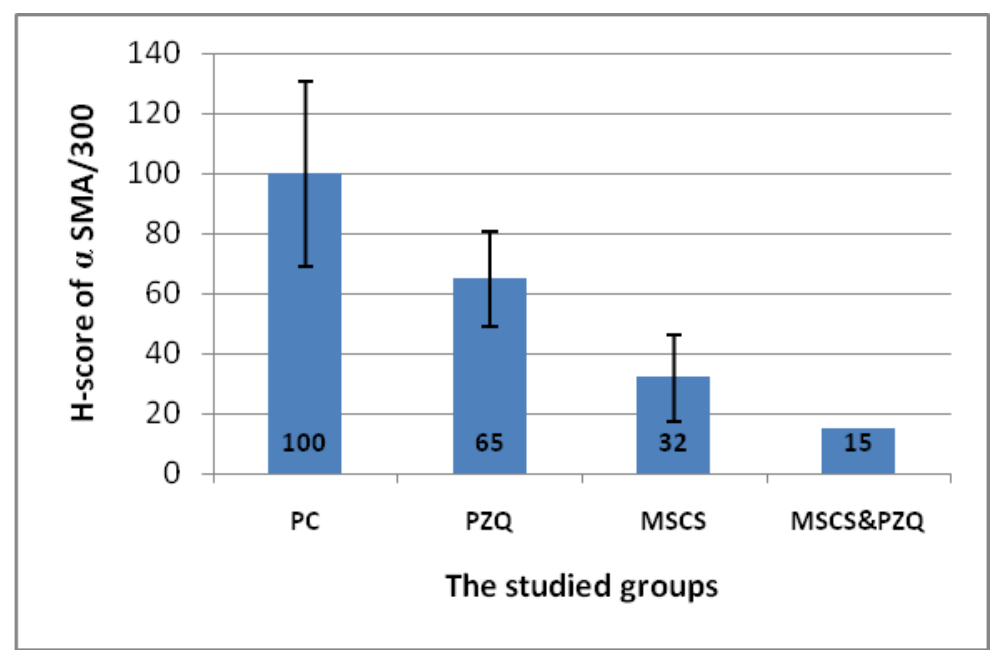

In the current study level of alanine transaminase (ALT), alkaline phosphatase (ALP) and albumin were assessed as functional parameters of the injured liver. Hanna et al., (2003) also reported injury of liver tissue as a result of $S$. mansoni infection which was accompanied by an increase in transaminases enzymes and decrease albumin level in serum. El-Rigal and Hetta (2006), referred the increase in liver enzymes to the cellular injury of the liver following deposition of eggs. El-mahdi et al., (2014) also, measured liver injury, as consequence to infection by Schistosomiasis, by elevation of ALT, ALP and decrease in albumin noting the reactive inflammatory response to infection. A significant decrease in ALT, significant increase in ALB and a significant decrease in ALP was recorded following treatment with BM-MSCs (Table 1). These result were in accordance to Mehrabani et al.,(2019) finding who found that the level of ALT was decreased signifying the effect of BMSCs on liver injury repairing in a study used the rat as an animal model. 


\section{Measuring Schistosomal liver fibrosis}

Histopathological examination revealed that the number of granulomas was significantly reduced in PZQ and PZQ/MSCs treated groups $(6.9 \pm 0.16$ and $4.28 \pm 1.82)$, while the increase in granuloma number was recorded in MSCs treated group (17.08 \pm 3.61$)$ compared to untreated mice (13.62 \pm 3.24$)$ (Fig. 2). Considering the mean size of granuloma, there was a non-statistical significant difference between different groups with the smallest granuloma size was represented in PZQ/MSCs (243.64 \pm 58.8 ), followed by MSCs (254.9 \pm 70.65$)$ and larger granuloma in PZQ treated group $(265.2 \pm 0.0)$. Using Masson trichrome staining, percent of fibrosis was reduced in MSCs and $\mathrm{PZQ} / \mathrm{MSCs}$ treated groups $(\mathrm{P}=0.005$ and 0.02 respectively)while in PZQ treated group it was reduced but statistically not significant $(\mathrm{P}=0.21)$. Immunostaining by using $\alpha$ SMA revealed that fibrosis was reduced in MSCs (32.0 \pm 14.4 ; $\mathrm{P}=0.009), \mathrm{PZQ} / \mathrm{MSCs}(15.0 \pm 0.0 ; \mathrm{P}=0.005)$ and in PZQ treated group $(65.0 \pm 15.81$; $\mathrm{P}=0.045)$ compared to infected untreated mice (Fig. 3, 4, 5, 6 and Table 3).

Regarding histopathological results, significant recovery of fibrosed liver tissue was observed using $\mathrm{H} \& \mathrm{E}$ which was manifested by decrease granuloma number and which was measured by some authors before. They noted the same effect of MSCs on granuloma (Aziz et al., 2007). Also, Mohammed et al., (2014) noted the improvement of liver architecture after the use of MSCs. Collagen deposition and fibrosis of the liver were assessed using Masson Trichrome stain with the resultant formation of blue-stained collagen fibers. Our work stated that collagen fibers amount was markedly increased in S. mansoni infection and significantly decreased after the use of PZQ and MCSs (Table 3).
Wu et al., (2018), observed that the reduction of fibrosis was accompanied by a lower number of activated HSCs which are the main cells responsible for creating ECM components in the liver, and must be activated and then differentiated into a myofibroblastlike cell.

In addition to histopathological work up immunostaining marker alpha-smooth muscle actin was investigated to detect degree of fibrosis and to analyze the method by which MSCs alleviate fibrosis (Fig. 8). Jang et al., (2015) found that decrease in the number of $\alpha$ SMA+ cells in liver tissues treated with BMMCs was probably due to modulation of HSCs by specific cytokines and growth factors, including TGF- $\beta 1$, TNF- $\alpha$, and ROS, which resulted from liver injury and mediated by the autocrine and paracrine signaling activation of HSCs. Zhang et al., (2019) found that BM-MSCs inoculation diminished $\alpha-$ SMA expression in liver tissues.

Measuring serum level of HA in our study revealed that serumhyaluronic acid was significantly elevated in infected untreated mice than uninfected ones $(\mathrm{P}=<0.001)$.

Comparing between treated groups and untreated mice showed that no statistical significant difference between infected untreated mice and PZQ group $(\mathrm{P}=0.34)$, however, MSCS group [P=0.01] or MSCS \& PZQ group $[\mathrm{P}=0.009]$ showed statistically significant lower levels of hyaluronic acid when compared with infected untreated mice (Table 4 and Fig. 7).

HA is considered a strong noninvasive marker of the grade of liver fibrosis (Popper and Kent, 1975 \&Shigemori et al., 2002). We examined HA titers in mice following S. mansoni infection and the association between the HA titers and the liver fibrosis degree was assessed. Our results showed that liver fibrosis 
were positively correlated with the serum level of HA in mice infected with S. mansoni. other studies confirmed this finding, the concentrations of serum markers of liver fibrosis were significantly lower in the infected mice with $S$. jabonicum and treated with MSCs than those in the untreated infected mice which confirmed the anti-fibrotic effects of the administration of stem cells (Qiu et al., 2014) (Table 4).

This study has experimentally explored the role of MSCs in the alleviation of liver fibrosis induced by Schistosoma mansoni (Egyptian strain) infection. Moreover, it highlights the use of HA as a marker for evaluating fibrosis giving nearly the same results reported by immunostaining and histopathological examination which facilitate the coming researches in noninvasive measuring of fibrosis.

\section{Acknowledgment}

The authors would like to thank Dr/ Mohamed Salah (animal house department) and Dr/ Mohamed ElZallat (stem cell department) TBRI for their helpful assistance through the work. No assistance was received in writing.

\section{Financial support}

This work received funding from Menoufia university project research unit.

\section{References}

Ali, Sanaa A, and Manal A Hamed. 2006. "Effect of Ailanthus altissima and Zizyphus spina Christi on Bilharzial Infestation in Mice: Histological and Histopathological Studies." J Appl Sci 6 (7): 1437-46.

"Ameliorative Effect of Bone MarrowDerived Stem Cells on Injured Liver of Mice Infected with Schistosoma mansoni." 201452 (2): 151-62.

Anan, Hoda H, Rania A Zidan, Mohammad A Shaheen, and Enas A Abd-El Fattah. 2016. "Therapeutic Efficacy of Bone Marrow Derived Mesenchymal Stromal Cells versus Losartan on Adriamycin-Induced Renal Cortical Injury in Adult Albino Rats.' Cytotherapy 18 (8): 970-84.

Aziz, M T Abdel, H M Atta, S Mahfouz, H H Fouad, N K Roshdy, H H Ahmed, L A Rashed, D Sabry, A A Hassouna, and N M Hasan. 2007. "Therapeutic Potential of Bone Marrow-Derived Mesenchymal Stem Cells on Experimental Liver Fibrosis." Clinical Biochemistry 40 (12): 893-99.

Cheever, ALLEN W. 1968. "Conditions Affecting the Accuracy of Potassium Hydroxide Digestion Techniques for Counting Schistosoma Mansoni Eggs in Tissues." Bulletin of the World Health Organization 39 (2): 328.

Chuah, Candy, Malcolm K Jones, Melissa L Burke, Donald $\mathrm{P}$ McManus, and Geoffrey N Gobert. 2014. "Cellular and Chemokine-Mediated Regulation in Schistosome-Induced Hepatic Pathology." Trends in Parasitology 30 (3): 141-50.

Cioli, Donato, Livia Pica-Mattoccia, Annalisa Basso, and Alessandra Guidi. 2014. "Schistosomiasis Control: Praziquantel Forever?" Molecular and Biochemical Parasitology 195 (1): 23-29.

Colley, Daniel G, Amaya L Bustinduy, W Evan Secor, and Charles $\mathrm{H}$ King. 2014. "Human Schistosomiasis." The Lancet 383 (9936): 2253-64.

Duvall, Rodney $\mathrm{H}$, and William B DeWitt. 1967. "An Improved Perfusion Technique for Recovering Adult Schistosomes from Laboratory Animals." The American Journal of Tropical Medicine and Hygiene 16 (4): 483-86. 
El-Mahdi, Magda M, Wafaa A Mansour, Olfat Hammam, Noha A Mehana, and Taghreed M Hussein. 2014. "Ameliorative Effect of Bone MarrowDerived Stem Cells on Injured Liver of Mice Infected with Schistosoma Mansoni." The Korean Journal of Parasitology 52 (2): 151.

El-Rigal, Nagy-Saba, and Mona H Hetta. 2006. "Effect of Citrus reticulata on Serum Protein Fractions of Mice after Schistosoma Mansoni Infection." $J$ Appl Sci 6 (7): 1447-55.

Hanna, L S, A M Medhat, and H A AbdelMenem. 2003. "Biochemical Changes after Subchronic and Chronic Interaction of Schistosoma mansoni Infection in Swiss Albino Mice with Two Specific Compounds." Journal of the Egyptian Society of Parasitology 33 (1): 245-60.

Hegab, Mohamed H, Somia H Abd-Allah, Maha S Badawey, Ayman A Saleh, Ashraf S Metwally, Ghada M Fathy, Soad M Nada, Sara A Abdel-Rahman, Amira A Saleh, and Mohammed Abu El-Magd. 2018. "Therapeutic Potential Effect of Bone Marrow-Derived Mesenchymal Stem Cells on Chronic Liver Disease in Murine Schistosomiasis Mansoni." Journal of Parasitic Diseases 42 (2): 277-86.

Hotez, Peter J, Miriam Alvarado, MaríaGloria Basáñez, Ian Bolliger, Rupert Bourne, Michel Boussinesq, Simon J Brooker, Ami Shah Brown, Geoffrey Buckle, and Christine M Budke. 2014. "The Global Burden of Disease Study 2010: Interpretation and Implications for the Neglected Tropical Diseases." PLoS Neglected Tropical Diseases 8 (7): e2865.

James, Spencer L., Degu Abate, Kalkidan Hassen Abate, Solomon M. Abay, Cristiana Abbafati, Nooshin Abbasi, Hedayat Abbastabar, et al., 2018.
"Global, Regional, and National Incidence, Prevalence, and Years Lived with Disability for 354 Diseases and Injuries for 195 Countries and Territories, 1990-2017: A Systematic Analysis for the Global Burden of Disease Study 2017." The Lancet, 1789-1858.

https://doi.org/10.1016/S01406736(18)32279-7.

Jang, Yoon Ok, Baek Gyu Jun, Soon Koo Baik, Moon Young Kim, and Sang Ok Kwon. 2015. "Inhibition of Hepatic Stellate Cells by Bone MarrowDerived Mesenchymal Stem Cells in Hepatic Fibrosis." Clinical and Molecular Hepatology 21 (2): 141.

Jiraungkoorskul, Wannee, Somphong Sahaphong, Prasert Sobhon, Suda Riengrojpitak, and Niwat Kangwanrangsan. 2005. "Effects of Praziquantel and Artesunate on the Tegument of Adult Schistosoma mekongi Harboured in Mice." Parasitology International 54 (3): 177-83.

Johnston, E. Anna, Jordan Teague, and Jay P. Graham. 2015. "Challenges and Opportunities Associated with Neglected Tropical Disease and Water, Sanitation and Hygiene Intersectoral Integration Programs Global Health." BMC Public Health 15 (1): 1-14. https://doi.org/10.1186/s12889-0151838-7.

Kang, S H, M Y Kim, Y W Eom, and S K Baik. 2019. "Mesenchymal Stem Cells for the Treatment of Liver Disease: Present and Perspectives." Gut and Liver.

Liu, Wei- hui, Fu- qiang Song, Li- na Ren, Wen- qiong Guo, Tao Wang, Ya- xing Feng, Li- jun Tang, and Kun Li. 2015. "The Multiple Functional Roles of Mesenchymal Stem Cells in Participating in Treating Liver 
Diseases." Journal of Cellular and Molecular Medicine 19 (3): 511-20.

Mehrabani, D, Z Khajehahmadi, P Tajik, A Tamadon, F Rahmanifar, M Ashraf, N Tanideh, and S Zare. 2019. "Regenerative Effect of Bone MarrowDerived Mesenchymal Stem Cells in Thioacetamide-Induced Liver Fibrosis of Rats." Archives of Razi Institute 74 (3): 279-86.

Mohammed, N R, R H Ahmed, N K Roshdy, M I Aref, N M Hassan, and H E Saleh. 2014. "Effect of Bone MarrowDerived Mesenchymal Stem Cells and Umbilical Cord Blood-CD34+ Cells on Experimental Rat Liver Fibrosis." Int $J$ Stem Cell Res Transplant 2 (03): 6368.

Peters, Pierre A, and Kenneth S Warren. 1969. "A Rapid Method of Infecting Mice and Other Laboratory Animals with Schistosoma Mansoni: Subcutaneous Injection." Journal of Parasitology 55 (3).

Popper, Hans, and Geottrey Kent. 1975. "Fibrosis in Chronic Liver Disease." Clinics in Gastroenterology 4 (2): 315-32.

Qiu, Wenhong, Kaiwen Guo, Luyang Yi, Yeli Gong, Lixia Huang, and Wei Zhong. 2014. "Resolvin E1 Reduces Hepatic Fibrosis in Mice with Schistosoma Japonicum Infection.” Experimental and Therapeutic Medicine 7 (6): 148185.

Shigemori, Masahiko, Syuji Takei, Hiroyuki Imanaka, Nobuaki Maeno, Masashi Hokonohara, and Koichiro Miyata. 2002. "Diagnostic Significance of Increased Serum Hyaluronic Acid in Juvenile Rheumatoid Arthritis." Pediatrics International 44 (4): 39499.

Singh, Kameshwar P, Herve C Gerard, Alan P Hudson, and Dov L Boros. 2004. "Expression of Matrix
Metalloproteinases and Their Inhibitors during the Resorption of Schistosome Egg- induced Fibrosis in Praziquantel- treated Mice." Immunology 111 (3): 343-52.

Soleimani, Masoud, and Samad Nadri. 2009. "A Protocol for Isolation and Culture of Mesenchymal Stem Cells from Mouse Bone Marrow." Nature Protocols 4 (1): 102.

Suzuki, Ayako, Paul Angulo, James Lymp, Dave Li, Shinji Satomura, and Keith Lindor. 2005. "Hyaluronic Acid, an Accurate Serum Marker for Severe Hepatic Fibrosis in Patients with Non- alcoholic Fatty Liver Disease." Liver International 25 (4): 779-86.

Tamaki, Seishu, Takato Ueno, Takuji Torimura, Michio Sata, and Kyuichi Tanikawa. 1996. "Evaluation of Hyaluronic Acid Binding Ability of Hepatic Sinusoidal Endothelial Cells in Rats with Liver Cirrhosis." Gastroenterology 111 (4): 1049-57.

Vos, Theo, Christine Allen, Megha Arora, Ryan M Barber, Zulfiqar A Bhutta, Alexandria Brown, Austin Carter, Daniel C Casey, Fiona J Charlson, and Alan Z Chen. 2016. "Global, Regional, and National Incidence, Prevalence, and Years Lived with Disability for 310 Diseases and Injuries, 1990-2015: A Systematic Analysis for the Global Burden of Disease Study 2015." The Lancet 388 (10053): 1545-1602.

$\mathrm{Wu}, \mathrm{Yi}, \mathrm{Yu} \mathrm{Wu}, \mathrm{I}-\mathrm{Fen}$ Chen, Yi-Lung Wu, Chin Chuang, Han Huang, and Shyh Kuo. 2018. "Reparative Effects of Astaxanthin-Hyaluronan Nanoaggregates against RetrorsineCCl4-Induced Liver Fibrosis and Necrosis." Molecules 23 (4): 726.

Xu, Huijuan, Hui Qian, Wei Zhu, Xu Zhang, Yongmin Yan, Fei Mao, Mei Wang, Huitao Xu, and Wenrong Xu. 2012. "Mesenchymal Stem Cells Relieve 
Fibrosis of Schistosoma japonicumInduced Mouse Liver Injury." Experimental Biology and Medicine 237 (5): 585-92.

Yang, X, P M Van Der Kraan, Z Bian, M Fan, $\mathrm{X} F$ Walboomers, and $\mathrm{J}$ A Jansen. 2009. "Mineralized Tissue Formation by BMP2-Transfected Pulp Stem Cells." Journal of Dental Research 88 (11): 1020-25.

Zhang, Liting, Dan Zhou, Junfeng Li, Xiaoming Yan, Jun Zhu, Ping Xiao, Tuo Chen, and Xiaodong Xie. 2019. "Effects of Bone Marrow-Derived
Mesenchymal Stem Cells on Hypoxia and the Transforming Growth Factor Beta 1 (TGFß-1) and SMADs Pathway in a Mouse Model of Cirrhosis." Medical Science Monitor. https://doi.org/10.12659/msm.916428.

Zhao, Lu, Shanquan Chen, Xiaowei Shi, Hongcui Cao, and Lanjuan Li. 2018. "A Pooled Analysis of Mesenchymal Stem Cell-Based Therapy for Liver Disease." Stem Cell Research \& Therapy 9 (1): 72.

\section{How to cite this article:}

Marwa Ahmed Gouda, Asmaa Shams El Dein Mohamed, Fatma Eldesoky Ahmed, Ghada Samir Amer and Dalia Shafey. 2019. Antifibrotic Alleviative Effect of Bone Marrow-Derived Mesenchymal Stem Cells on Experimentally induced Schistosoma mansoni Related Liver Fibrosis. Int.J.Curr.Microbiol.App.Sci. 8(12): 1136-1151.

doi: https://doi.org/10.20546/ijcmas.2019.812.143 